\title{
Ultrashort echo-time MRI as a substitute to CT for skull aberration correction in transcranial focused ultrasound: in vitro comparison on human calvaria
}

Jean-Francois Aubry ${ }^{*}$, Matt Eames ${ }^{2}$, John Snell ${ }^{2}$, Wilson Miller ${ }^{1}$

From Current and Future Applications of Focused Ultrasound 2014. 4th International Symposium Washington, D.C, USA. 12-16 October 2014

\section{Background/introduction}

Clinical transcranial MR-guided focused ultrasound (TcMRgFUS) brain treatment systems compensate for skull-induced beam aberrations by adjusting the phase and amplitude of individual ultrasound transducer elements. These corrections are currently calculated based on a pre-acquired CT scan of the patient's head. The purpose of the work presented here is to demonstrate the feasibility of using ultrashort echo-time (UTE) MRI instead of CT to calculate and apply aberration corrections on a clinical TcMRgFUS system.

\section{Methods}

Phantom experiments were performed in three ex vivo human skulls filled with tissue mimicking hydrogel. Each skull phantom was imaged with both CT and UTE
MRI. The MR images were then segmented into "skull" and "not-skull" pixels using a computationally efficient, threshold-based algorithm, and the resulting threedimensional binary skull map was converted into a series of two-dimensional virtual CT images. Each skull was mounted in the head transducer of a clinical TcMRgFUS system (ExAblate Neuro, Insightec, Israel), and transcranial sonications were performed using a power setting of approximately 750 Acoustic Watts at several different target locations within the electronic steering range of the transducer. Each target location was sonicated three times: once using aberration corrections calculated from the actual CT scan, once using corrections calculated from the MRI-derived virtual CT scan, and once without applying any aberration correction. MR thermometry was performed in conjunction

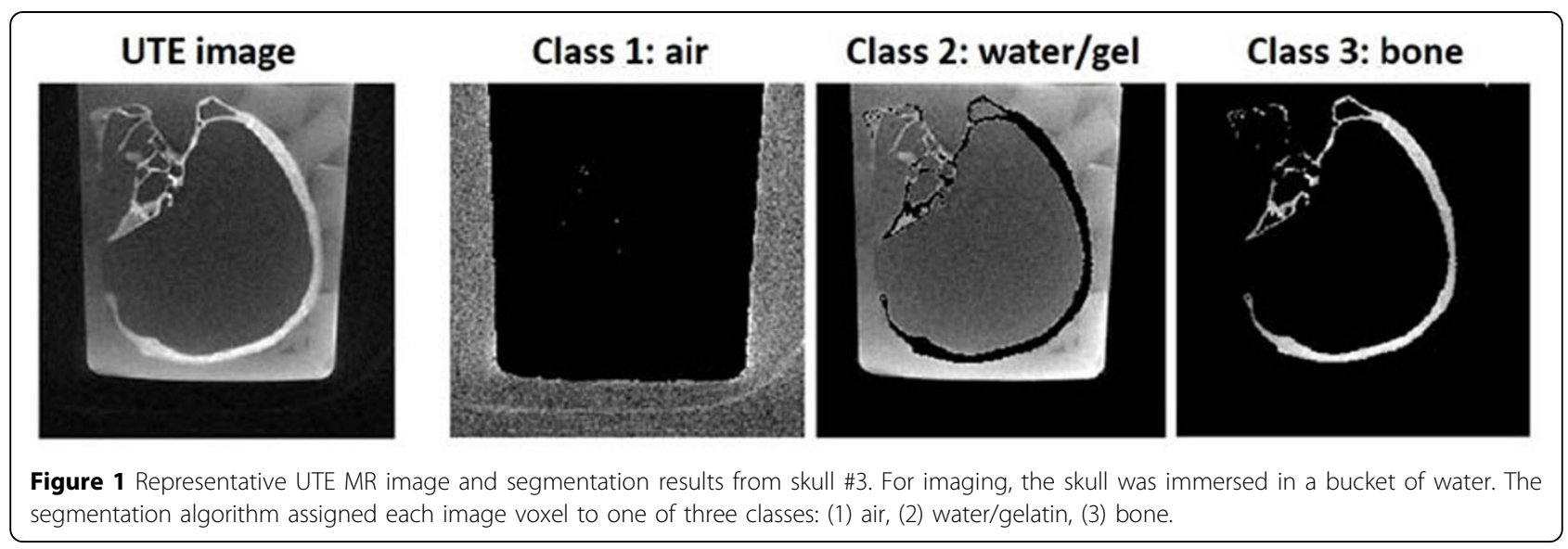

'University of Virginia, Charlottesville, Virginia, United States

Full list of author information is available at the end of the article 

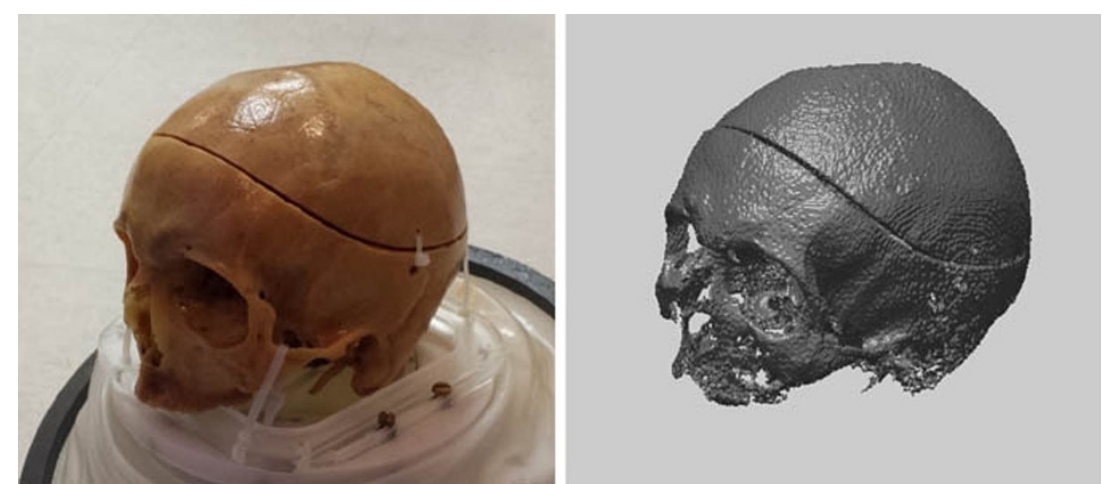

Figure 2 Photograph of one of the skull phantoms (\#2), and a 3D surface rendering generated from the MR-derived bone map.

with each 10-second sonication, and the highest singlepixel temperature rise and surrounding-pixel mean were recorded for each sonication.

\section{Results and conclusions}

Fig. 1 shows a UTE MR image and segmentation results from one of the skull phantoms. Fig. 2 shows a photograph of another skull phantom along with a 3D surface rendering generated from the binary bone map. The sonication results are summarized in Fig. 3. The measured temperature rises were $\sim 45 \%$ larger for aberrationcorrected sonications than for non-corrected sonications.

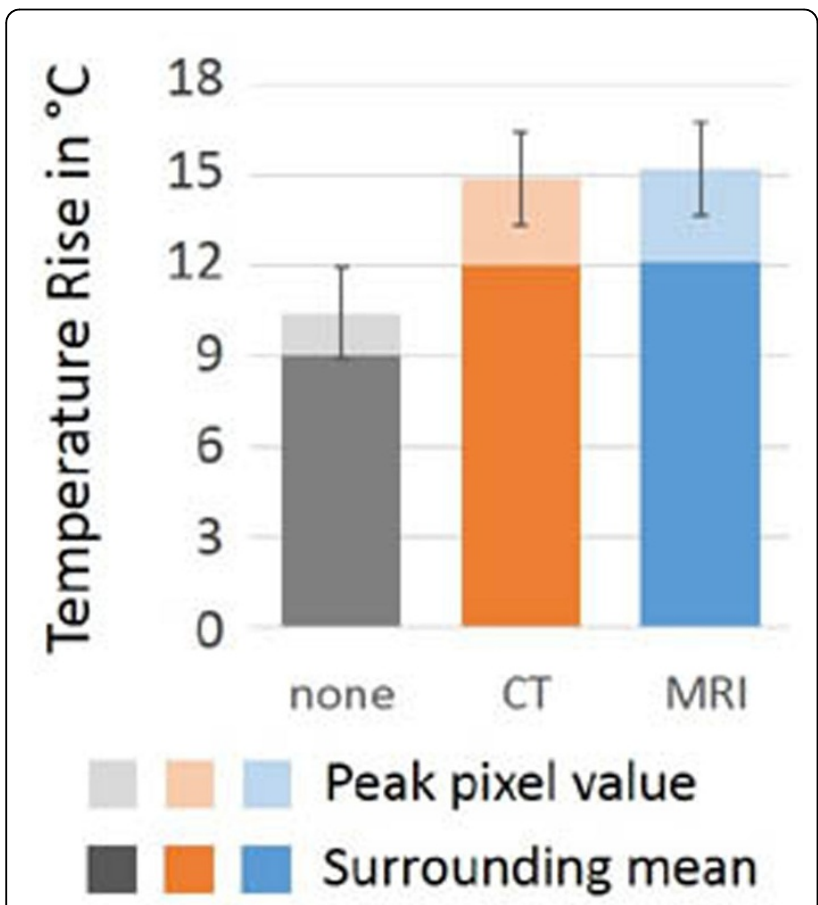

Figure 3 Graphical summary of sonication results. Each bar represents the average temperature rise of all sonications performed in all skulls using the same aberration correction method (none, CT-based, or MR-based).
This improvement was highly significant $(\mathrm{p}<10-4)$. The difference between the single-pixel peak temperature rise and the surrounding pixel mean, which reflects the sharpness of the thermal focus, was also significantly larger for aberration-corrected sonications. There was no significant difference between the sonication results achieved using CT-based and MR-based aberration correction.

\section{Acknowledgements (Funding)}

Jean-Francois Aubry is a consultant for the Focused Ultrasound Foundation.

\section{Authors' details}

'University of Virginia, Charlottesville, Virginia, United States. ${ }^{2}$ Focused Ultrasound Foundation, Charlottesville, Virginia, United States.

Published: 30 June 2015

doi:10.1186/2050-5736-3-S1-P12

Cite this article as: Aubry et al:: Ultrashort echo-time MRI as a substitute to CT for skull aberration correction in transcranial focused ultrasound: in vitro comparison on human calvaria. Journal of Therapeutic Ultrasound 2015 3(Suppl 1):P12.

\section{Submit your next manuscript to BioMed Central} and take full advantage of:

- Convenient online submission

- Thorough peer review

- No space constraints or color figure charges

- Immediate publication on acceptance

- Inclusion in PubMed, CAS, Scopus and Google Scholar

- Research which is freely available for redistribution 